\title{
REACTION OF CITRIC ACID WITH CALCITE
}

\author{
by \\ MOHAMMED ALKHALDI \\ submitted to the Graduate Center \\ in partial fulfillment of the requirements \\ for the degree of
}

DOCTOR OF PHII,OSOPHY

UNIVERSITY of ADELAIDE

AUSTRALIAN SCHOOL of PETROLEUM (ASP)

June 2009

Major Subject: Petroleum Engineering 


\section{TABLE OF CONTENTS}

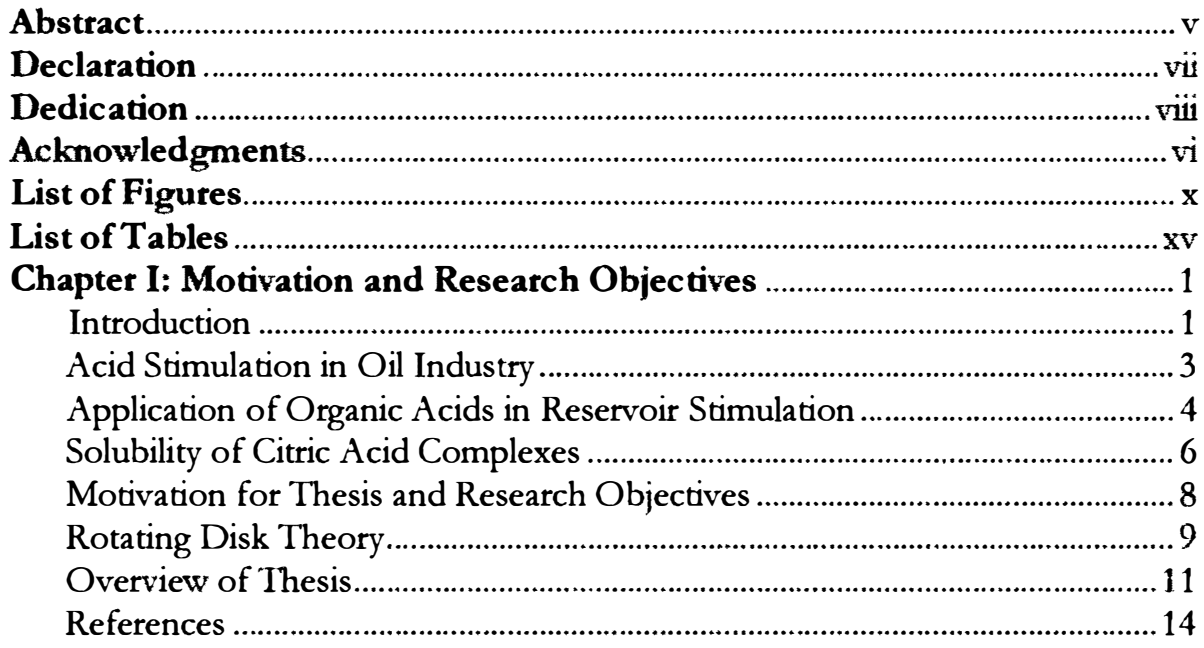

Chapter II: Impact of Calcium Citrate Precipitation on Citric-Calcite

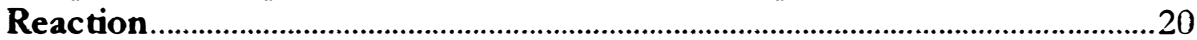

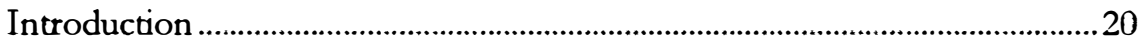

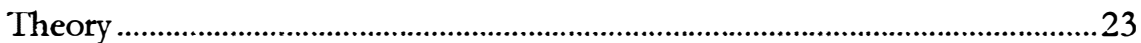

Dissociation and Chelation Chemistry of Citric Acid ....................................23

Mass Transfer into a Rotating Disk in Reactive Environments ...................27

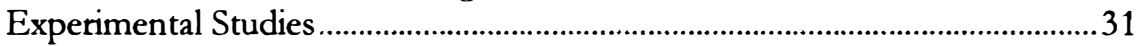

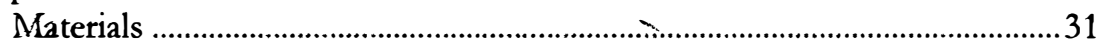

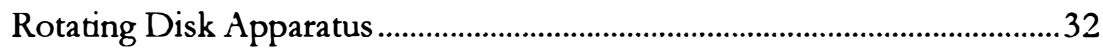

Morphology and Composition of the Disk Surface .......................................34

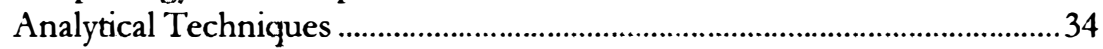

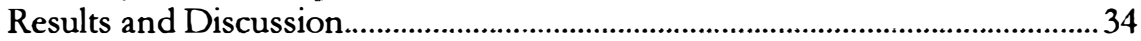

Reproducibility and Effect of Long Reaction Time ....................................34

Calculation of the Diffusion Coefficient of Cirric Acid.................................37

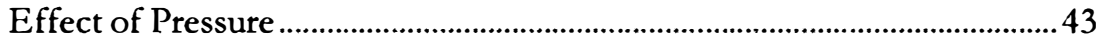

Calcium Citrate Precipitation-SEM Studies....................................................46

Effect of Disk Rotational Speed on Calcium Citrate Layer ................. 50

Effect of System Pressure on Calcium Citrate Layer............................. 54

Effect of Iron (III) and Magnesium on Calcium Citrate Precipitation ......56

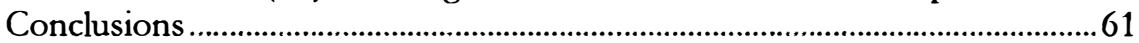

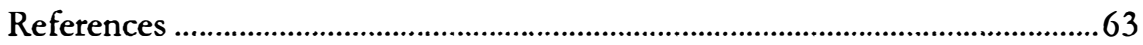

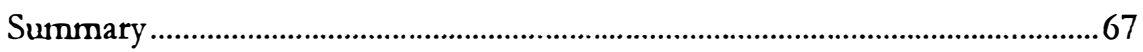


Chapter III: The diffusivity of citric acid in its reaction solutions with calcite

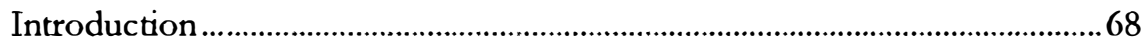

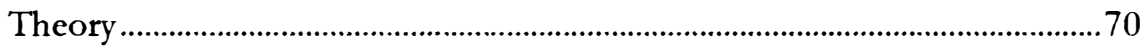

Chemistry of Citric Acid and Precipitation of Calcium Citrate ....................70

Mass Transfer into a Rotating Disk in Reactive Environments ...................72

Mobility of Citric Acid in Aqueous Solutions ................................................74

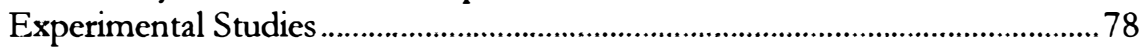

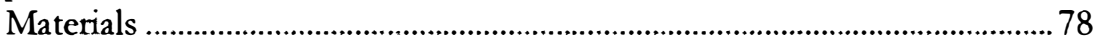

Rotating Disk Apparatus .................................................................................. 78

Analytical Techniques ................................................................................79

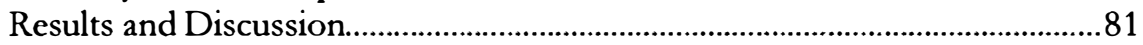

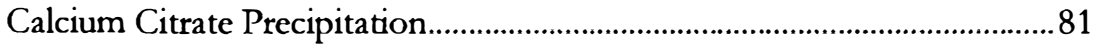

Species Distribution during Citric-Calcite Reaction.......................................83

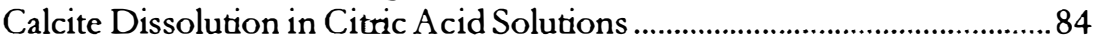

Effect of Initial Citric Acid Concentration on its Diffusion Coefficient ...91

Effect of Initial Citric Acid Concentration on its Effective Diffusion Coefficient.......................................................................................................95

Effect of Temperature on the Effective Diffusion Coefficient of Citric

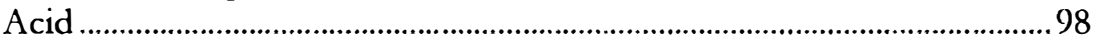

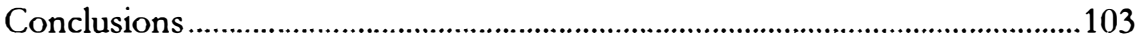

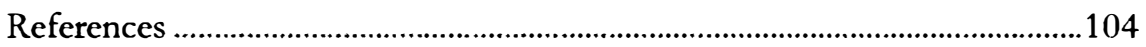

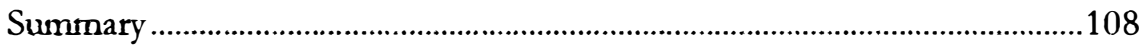

Chapter IV: Kinetics of the reaction of citric acid with calcite ....................109

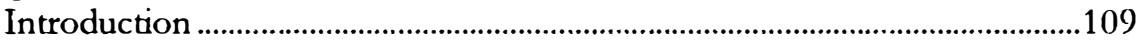

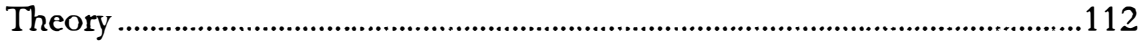

Dissociation of Weak Acids...........................................................................112

Acid Carbonate Reaction ..............................................................................114

Mass Transfer into a Rotating Disk in Reactive Environments .................117

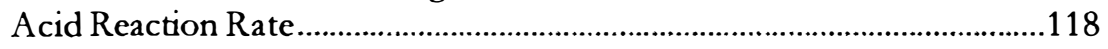

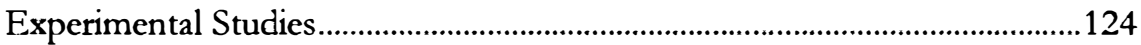

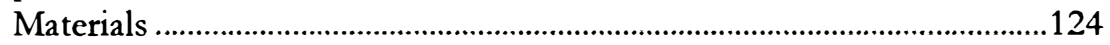

Rotating Disk Apparatus.........................................................................124

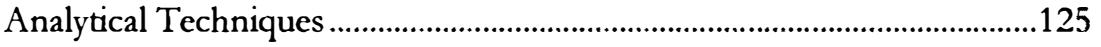

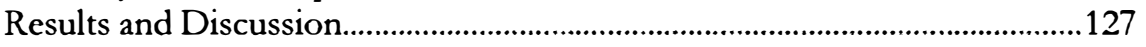

Calcium Concentration and Dissolution Rate............................................127

Calcium Citrate Precipitation............................................................................130

Kinetics Study of Citric Acid Reaction with Calcite ....................................130

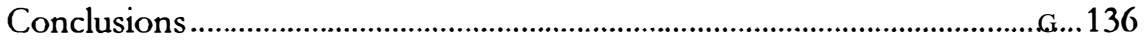

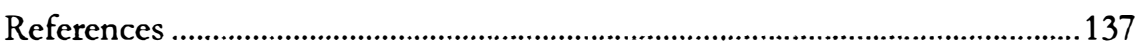

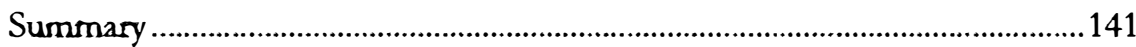

Chapter V: Conclusions and Recommendations ...............................................142 


\title{
UNIVERSITY $\odot$ F ADELAIDE
}

\author{
ABSTRACT \\ Reaction of Citric Acid with Calcite \\ by Mohammed Alkhaldi
}

This study is the first one to examine the reaction of citric acid with calcite over a wide range of parameters. Its main focus is to study the effects of different parameters such as initial citric acid concentration and temperature on the citriccalcite reaction.

A rotating disk apparatus was used to study the reaction of calcite $\left(\mathrm{CaCO}_{3}\right)$ with citric acid. Using the rotating disk theory, the calcite dissolution rates in citric acid solutions were evaluated as a function of rotating speed, initial concentration of citric acid, concentration of magnesium $\left(\mathrm{Mg}^{2+}\right) \&$ Iron $\left(\mathrm{Fe}^{3+}\right)$ ions, temperature, and pressure. In addition, Scanning Electron Microscopy (SEM) technique was used to explore the precipitation mechanism of calcium citrate during the reaction of citric acid with calcite. Using this technique, several factors affecting the precipitation of calcium citrate were identimed.

In this research, citric acid was found to be an effective stimulation fluid at $\mathrm{pH}$ values $<4$, rotational speeds of $(100-1,000 \mathrm{rpm})$, initial citric acid concentration of $1-7.5 \mathrm{wt} \%$, pressure values of $1,000-1,500 \mathrm{psi}$, and temperatures of $25-50{ }^{\circ} \mathrm{C}$. However, SEM analysis has shown that calcium citrate precipitation occurred during the reaction at the calcite disk. The precipitation of calcium citrate was found be function of disk rotational speed, initial citric acid concentration, and the concentration of both $\mathrm{Mg}^{2+}$ and $\mathrm{Fe}^{3+}$ ions. More calcium citrate precipitated at high rotational speeds and high initial citric acid concentration. The presence of both $\mathrm{Mg}^{2+}$ and $\mathrm{Fe}^{3+}$ ions minimized the precipitation of calcium citrate. 
The rate of calcite dissolution in citric acid was found to be mainly dependent on the rotational speed. In general, at low rotational speeds, below $500 \mathrm{rpm}$, the calcite dissolution is mainly governed by the mass-transfer rate, while at high rotational speed, above $500 \mathrm{rpm}$, it is controlled by the surface-reaction rate. The mass-transfer and the surface-reaction mechanism were investigated thoroughly.

Using the rotating disk theory, the overall mass transfer coefficient was determined at various rotational speeds, initial citric acid concentrations, and temperature values. The effective diffusion coefficient of citric as was determined at various citric acid concentrations and various temperature values. In addition, the apparent activation energy of calcite dissolution in mass-transfer regime was found to be $37.9 \mathrm{~kJ} / \mathrm{mol}$. Finally, a simplified expression was developed to model the reaction kinetics of citric acid with calcite. The model parameters: reaction order, and activation energy were found to be $\mathbf{0 . 8 3 3}$ and $\mathbf{6 3 . 1}$ $\mathrm{kJ} / \mathrm{mol}$, respectively.

This study highlights the importance of the initial acid concentration, temperature, and calcium citrate precipitation on the citric acid reaction with calcite. Another important outcome is the effect of various key parameters on the performance of citric acid as a stand-alone stimulation fluid at conditions similar to those present in a typical field case.

Findings based on this work provide new insights into the applications, usage, and potential limitations of citric acid. Factors controlling downhole reaction of citric acid with calcite are also disclosed. 